\title{
Editorial
}

Ophthalmologe $2020 \cdot 117: 296-297$ https://doi.org/10.1007/s00347-020-01095-5 Online publiziert: 30 . März 2020

(c) Springer Medizin Verlag GmbH, ein Teil von Springer Nature 2020

Peter Heiduschka · Jost L. Lauermann · Friederike D. Bosche · Nicole Eter

Universitäts-Augenklinik Münster, Münster, Deutschland

\section{Ein Schutz gegen die Tröpfcheninfektion an der Spaltlampe. Sicherheit für die Augenärzte UND die Patienten}

In $-\mathrm{Abb} .1$ ist die technische Zeich-

Gegenwärtig bereitet das neuartige SarsCoV-2 Virus unserer Gesellschaft ernsthafte Probleme. Eine wesentliche Ursache ist neben den immer noch fehlenden Möglichkeiten zur Behandlung und Impfung die leichte Übertragbarkeit des Virus über die Tröpfcheninfektion, besonders wenn der Abstand zwischen den Personen nicht genügend groß ist. Ein besonders problematischer Fall ist die augenärztliche Untersuchung an der Spaltlampe, bei welcher der Abstand zwischen dem Augenarzt und dem Patienten (die weiblichen mit eingeschlossen) gerade mal nur ca. $30 \mathrm{~cm}$ beträgt.

Im Netz kursieren deshalb bereits viele Ideen, wie die Gefahr einer Tröpfcheninfektion verringert werden kann, indem zwischen dem Patienten und dem Augenarzt eine als „Tröpfchenschutz“ fungierende Folie bzw. ein Schutzschild angebracht wird. Wir haben uns ebenfalls zu diesem Thema Gedanken gemacht und ein Schutzschild entworfen, welches unkompliziert an die in den meisten Praxen verwendete Spaltlampe von HaagStreit BQ 900 (Haag-Streit Deutschland, Wedel) angebracht werden kann. Anhand eines Prototyps testeten wir zunächst die Eignung des Schutzschildes, denn es durfte natürlich nicht die Untersuchung des Patienten behindern, bei welcher der Augenarzt mit der Hand um die Spaltlampe herum an das Auge des Patienten gelangen muss.

Dieser Beitrag erscheint zeitgleich auch in den Ophthalmologischen Nachrichten, Biermann Verlag GmbH, Köln. nung der anhand der Testung des Prototyps optimierten Version des Schutzschildes gezeigt. Die feinmechanische Werkstatt des Universitätsklinikums Münster fertigte nach dieser Zeichnung eine Reihe solcher Schutzschilde, mit denen wir die Spaltlampen unserer Klinik ausstatteten. Es besteht aus klarem PVC, ist also durchsichtig. Die Dicke kann variabel gestaltet werden, wir verwendeten Material von 3 bis $4 \mathrm{~mm}$ Dicke. Aufgrund des verwendeten Materials kann das Schutzschild mit den üblichen alkoholhaltigen Desinfektionsmitteln abgewischt werden, ohne daß das Schutzschild leidet.
Das Schutzschild wird an die Spaltlampe angebracht, indem das Okularteil abgenommen wird und es durch die auf der Zeichnung (• Abb. 1) erkennbare Öffnung hindurchgesteckt wird. Messungen an den verschiedenen bei uns vorhandenen Spaltlampen ergaben einen Durchmesser des Okularteils zwischen 74,8 und $76,2 \mathrm{~mm}$. Um eine gewisse Beweglichkeit des Schutzschildes zu gewährleisten, entschieden wir uns bei der Öffnung für einen Durchmesser von $77 \mathrm{~mm}$. An der Unterseite des Schutzschildes ließen wir eine Aussparung, um eine leichte Bedienbarkeit des Lenkhebels zu ermöglichen.

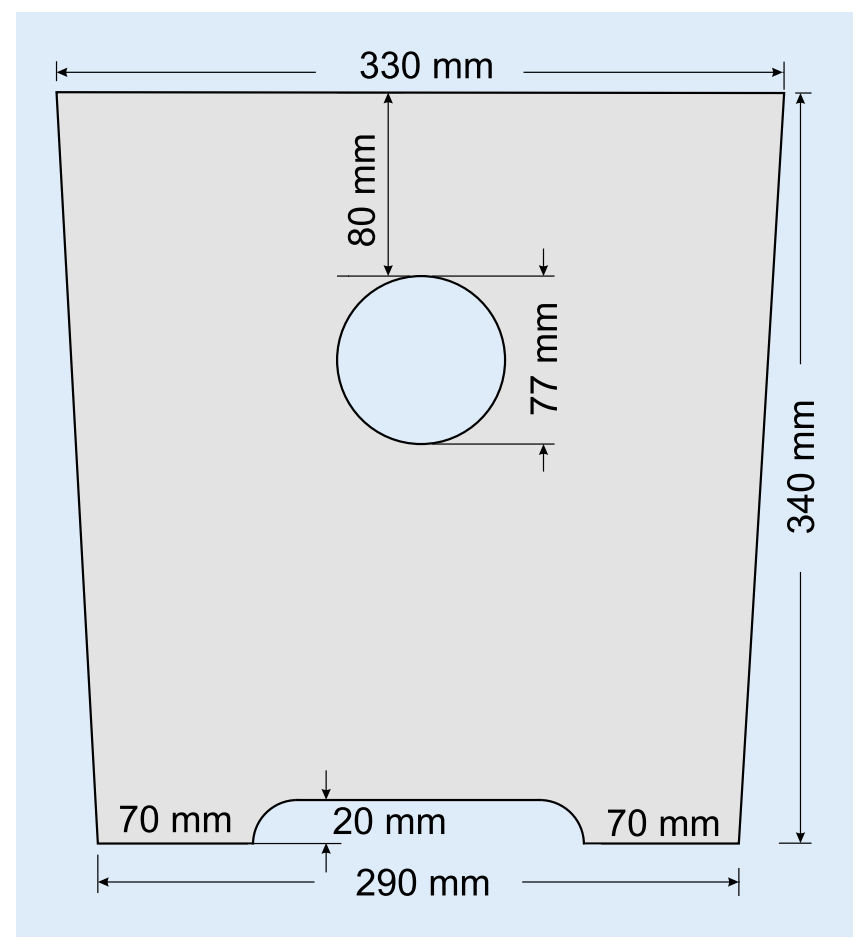

Abb. $1 \triangleleft$ Technische Zeichnung des SpaltlampenSchutzschildes, Material: klares PVC, Dicke 3-4 mm 


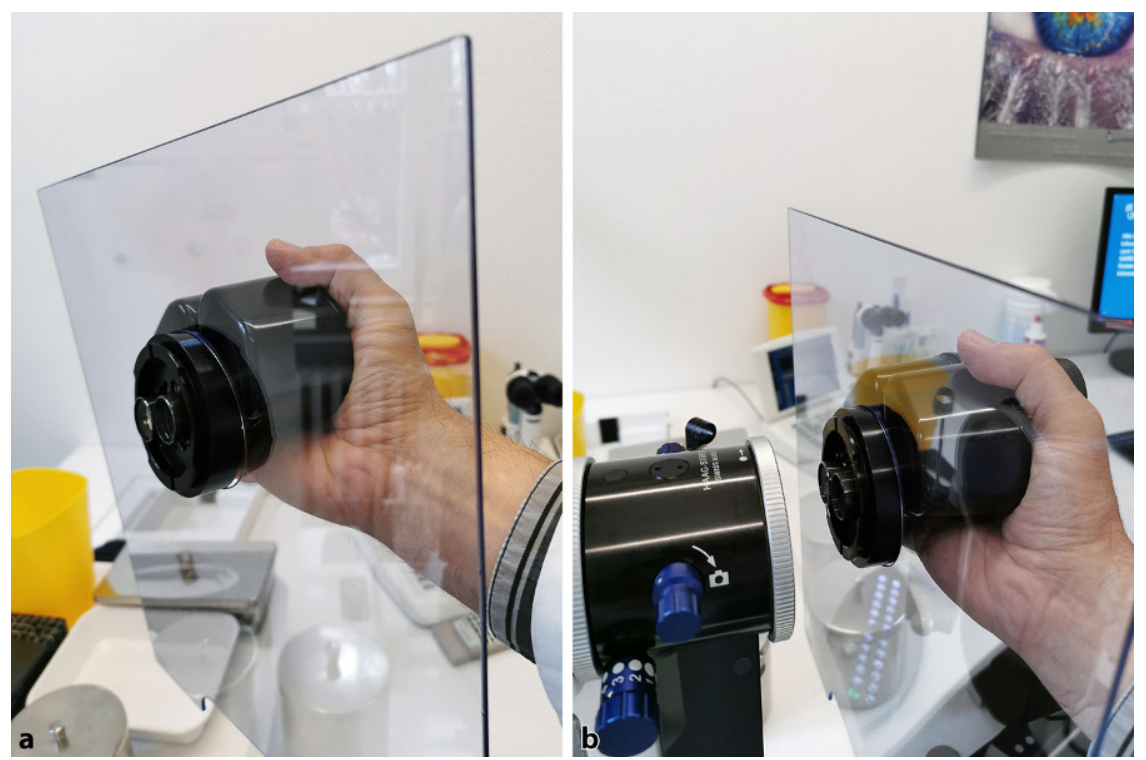

Abb. $2 \Delta$ a, b Aufstecken des Schutzschildes an das Okularteil der Spaltlampe
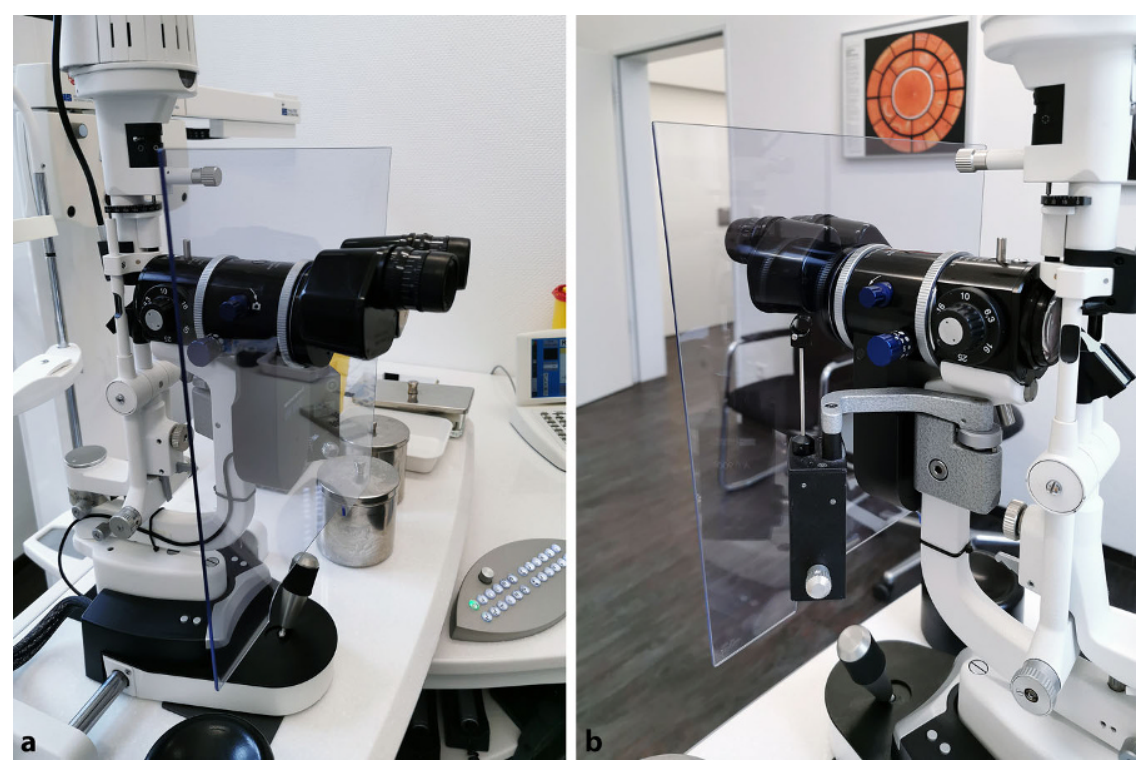

Abb. $3 \Delta$ a, b Ansicht der Spaltlampe nach Montage des Schutzschildes

\section{Infobox 1}

Die Universitäts-Augenklinik kann be der Herstellung dieser Schutzschilde Hilfestellung leisten. Bei Bedarf bitte an Herrn Prof. Dr. Peter Heiduschka wenden: peter.heiduschka@ukmuenster.de

Die - Abb. 2 und 3 zeigen das Aufstecken des Schutzschildes an das Okularteil der Spaltlampe sowie die Ansicht nach der Montage des Schutzschildes.

Mit diesem Schutzschild besteht ein guter Schutz gegen das direkte Anhauchen bzw. Anhusten, wodurch die Arbeit des Augenarztes einfacher wird. Die Patienten können sich ebenfalls sicherer fühlen.

Wir bitten, unsere Version des Schutzschildes als Anregung zu verstehen. Eine Nachahmung ist ausdrücklich erwünscht!

Prof. Dr. Peter Heiduschka Dr. Jost Lennart Lauermann Dr. Friederike Dorothee Bosche Univ.-Prof. Nicole Eter

\section{Korrespondenzadresse}

\section{Prof. Dr. Peter Heiduschka}

Universitäts-Augenklinik Münster

Domagkstraße 15, 48149 Münster, Deutschland peter.heiduschka@ukmuenster.de

Interessenkonflikt. P. Heiduschka, J.L. Lauermann, F.D. Bosche und N. Eter geben an, dass kein Interessenkonflikt besteht. 